\title{
First report on the prevalence of Fasciola hepatica in the endangered Père David's deer (Elaphurus davidianus) in China
}

\author{
Si-Yang Huang ${ }^{1,2^{*}} \mathbb{D}$, Jing-Zhi Gong ${ }^{1}$, Yi-Jun Ren ${ }^{3}$, Ming Pan ${ }^{1}$, Wei-Min Cai ${ }^{1}$, Yi-Min Fan ${ }^{1}$ and Na Yao
}

\begin{abstract}
Background: Fasciola hepatica is an important zoonotic parasite that causes fasciolosis in a broad range of animals. No information is available about the prevalence of F. hepatica in Père David's deer (Elaphurus davidianus), an endangered species in the world. Therefore, the purpose of the study was to evaluate the prevalence of fasciolosis in Père David's deer in the Dafeng Elk National Natural Reserve, Jiangsu province, China.

Results: In this study, 142 fecal samples from Père David's deer were analyzed for $F$. hepatica by microscopy and nest-PCR. Only one sample was positive for F. hepatica according to microscopy examination, while 18 of 142 (12.68, 95\%Cl: 2.841-22.45\%) samples were positive for F. hepatica according to nest-PCR results.

Conclusions: This is the first report of prevalence of $F$. hepatica in Père David's deer. The prevalence data indicated that $F$. hepatica was also present in this endangered animal, which may cause a potential threat to this precious species.
\end{abstract}

Keywords: Fasciola hepatica, Elaphurus davidianus, Nest-PCR, Prevalence, Internal transcribed spacer 2 (ITS-2)

\section{Background}

Fasciolosis is an important zoonotic disease, which can infect human and various animals, widely distributed in different countries in the world. It is estimated that this disease costs $€ 2.5$ billion economic losses in the global livestock production industry every year [1]. What's worse, overuse of triclabendazole (TCBZ) results in drug resistance in Fasciola spp. The anti-TCBZ strains had emerged in the Netherlands, Chile, Turkey and Peru, which had a huge impact on disease prevention and

\footnotetext{
* Correspondence: siyang.huang@hotmail.com

${ }^{1}$ Institute of Comparative Medicine, College of Veterinary Medicine,

Yangzhou University, and Jiangsu Co-innovation Center for Prevention and Control of Important Animal Infectious Diseases and Zoonosis, and Jiangsu Key Laboratory of Zoonosis, Yangzhou, Jiangsu Province 225009, People's Republic of China

${ }^{2}$ Joint International Research Laboratory of Agriculture and Agri-Product Safety, the Ministry of Education of China, Yangzhou UniversityYangzhou University, Jiangsu Province, Yancheng, People's Republic of China Full list of author information is available at the end of the article
}

control [2]. In China, the prevalence of fasciolosis in animals was quite high, $87.35 \%$ of buffaloes were infected by $F$. gigantic in Guangxi province, and $28.7 \%$ of Yaks were positive for $F$. hepatica in Gansu province [3, 4]. However, no information is available about $F$. hepatica infections in Père David's deer.

Père David's deer is an endangered deer species in the world, mainly distributed in China, the United States and the United Kingdom now. In 1986, 42 Père David's deer (13 males, 29 females) were re-introduced to the Dafeng Elk National Natural Reserve from UK, and the number of Père David's deer has been steadily increasing, reaching to 4556 in 2018. Here, we reported the prevalence of $F$. hepatica in Père David's deer in the Dafeng Elk National Natural Reserve. To our knowledge, this is the first prevalence of $F$. hepatica infection in these endangered animals. 


\section{Results}

\section{Faecal examination}

According to microscopy investigation result, F. hepatica eggs were only detected in one sample, with a size of about $68 \times 124 \mu \mathrm{m}$ (Fig. 1). Therefore, the prevalence of infection was only $0.70 \%(1 / 142)$, much lower than that in other species.

\section{Qualitative evaluation of nest-PCR tests}

One hundred forty-two Père David's deer fecal genomic DNA samples were examined by the nest-PCR with $F$. hepatica genomic DNA and PBS buffer used as positive and negative controls, respectively. There was a clear band at $200 \mathrm{bp}$ in the positive samples detected by nestPCR (Fig. 2). The PCR product of positive samples were sequenced, and then confirmed by blasting in Genebank. All sequences showed $100 \%$ identity to the standard $F$. hepatica 5.8S ribosomal RNA gene sequence (GenBank: MH715295.1), confirming that these samples are all infected by $F$. hepatica. To conclude, among 137 samples, 18 were positive for $F$. hepatica, and the prevalence is as high as $12.67 \%(95 \% \mathrm{CI}: 2.841-22.45 \%)$. Among the 18 positive samples, 6 samples were collected in 2017 and 12 samples were collected in 2018, the prevalence was $13.64 \% \quad(95 \% \mathrm{CI}: 3.496-23.77 \%)$ and $12.24 \%$ (95\%CI: 2.556-21.92\%), respectively (Table 1 ). There was no significant difference in the prevalence of these 2 years $(P>0.05)$.

\section{Discussion}

The Dafeng Elk National Natural Reserve is in Jiangsu province, with a warm and pleasant climate and abundant water source, and the environment provides

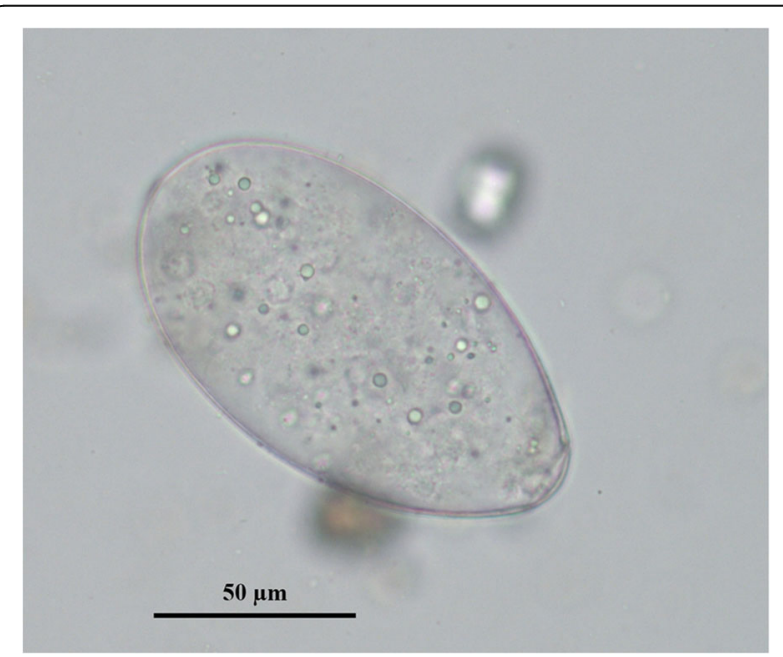

Fig. 1 Fecal microscopy examination. The No. 86 feces sample was treated by standard sedimentation method Microscopic observation multiple was $\times 400$. The width of the egg is $68.885 \mu \mathrm{m}$ and the length is $124.51 \mu \mathrm{m}$. Scale bars: $50 \mu \mathrm{m}$

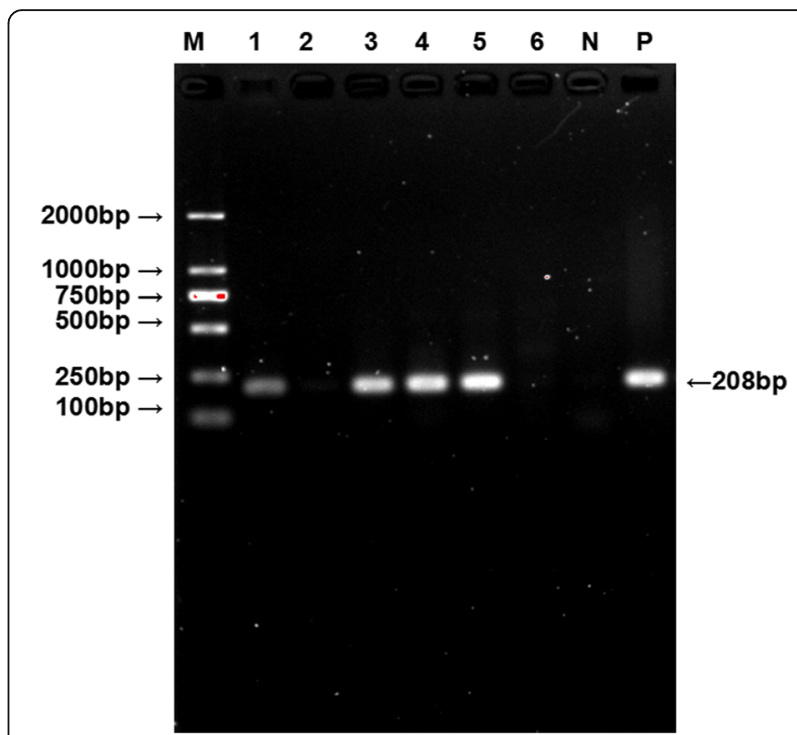

Fig. 2 Fecal samples were detected by the nest-PCR and PCR gel electrophoresis results of some samples. Lane 1-6: The result of second PCR run No. 17, 30, 45, 64, 86 and 98 DNA sample; N: PBS; P: positive DNA. M: 2000 bp DNA Marker (TaKaRa, Japan). The result showed No.17, 45, 64 and 86 samples were positive with a distinctly single band about 208 bp, No.30 and 98 samples were negative without any band

favorable conditions for survival and reproduction for the intermediate host of $F$. hepatica. Fasciolosis is an important disease for ruminants, so the prevalence of $F$. hepatica infection was evaluated in Chinese Père David's deer. In our study, only one sample was positive for the $F$. hepatic examined by fecal examination, while 18 samples were positive according to the nest-PCR analysis. The results showed that nest-PCR is more sensitive than the fecal examination. Therefore, in order to get better results, more sensitive detection methods like nest-PCRs should be chosen for fasciolosis surveillance in future.

Previous studies found that the prevalence of $F$. hepatica was $4.6 \%$ in Australia sika deer (Cervus nippon) [5], $29 \%$ in Spain roe deer (Capreolus capreolus) [6], 14.8\% in Argentinared deer (Cervus elaphus) [7], and 70\% in Ireland Fallow deer (Dama dama) [8], respectively. Our results showed that the prevalence is $12.67 \%$ in Père David's deer in the Dafeng Nature Reserve, which was lower than Spain roe deer, Argentinared deer and

Table 1 Prevalence of F. hepatica infection of Dafeng Elk National Natural Reserve, in China

\begin{tabular}{lllll}
\hline Year & No.Positive & No.Negative & $\begin{array}{l}\text { Prevalence(\%) } \\
(\mathbf{9 5 \%} \mathbf{C l})\end{array}$ & $P$ value \\
\hline 2017 & 6 & 38 & $13.64 \%(3.496-23.77 \%)$ & $>0.05^{\mathrm{a}}$ \\
2018 & 12 & 86 & $12.24 \%(2.556-21.92 \%)$ & \\
Total & 18 & 124 & $12.67 \%(2.841-22.45 \%)$ & \\
\hline
\end{tabular}

${ }^{a}$ The result was calculated by $\mathrm{X} 2$ test using SPSS21 (SAS Institute Inc., Cary, North Carolina, USA). All tests were two sided 
Ireland Fallow deer, but higher than Australia sika deer. The prevalence differences might due to the detection methods, living environment and other different factors. Although the Père David's deer in this study were wild animals, comparing to other wild animals, they were raised in closed area, having less chance of infection, because other ruminants were not allowed to enter this area. Given the reasons above, contaminated water or infected snails might play specific roles in the prevalence of $F$. hepatica infection.

Although there is no case about the anemia, diarrhea or death of Père David's deer caused by F. hepatica infection. Fasciolosis was reported in other deer species and bile duct lesions that has been linked to F. hepatica in wild sika deer in Japan [9]. Because Père David's deer like swimming, the Dafeng Nature Reserve located in swampland, the environment is suitable for snail reproduction and $F$. hepatica eggs development. This is a warning for the prevalence of fasciolosis in Père David's deer. It is important to carry out surveillance about fasciolosis in the Dafeng Elk National Natural Reserve. This study for the first time conducted molecular surveillance of the $F$. hepatica in Père David's deer, and provided basic data for this disease in this area.

\section{Conclusions}

In conclusion, this is the first prevalence of $F$. hepatica infection in wild Père David's deer. These results will provide useful information for establishing surveillance programs and basic data for future research on $F$. hepatica infection of Père David's deer.

\section{Methods}

\section{Ethics statement}

This study was approved by the Animal Ethics Committee of Yangzhou University and the sample collection was permitted by Ethics Committee of Dafeng Elk National Natural Reserve. All Père David's deer samples were handled in accordance with good animal practices required by the Animal Ethics Procedures and Guidelines of the People's Republic of China.

\section{Study area and sample collection}

The present study was conducted in the Dafeng Elk National Natural Reserve (120.46'44.66" 120.53'26.60"E, $\left.32.58^{\prime} 31.67^{\prime \prime} \sim 33.03^{\prime} 27.60^{\prime \prime} \mathrm{N}\right)$, which is located on the shore of the Yellow Sea. There are the largest wild elk population and largest elk gene bank in the world [10], and this area is very good for the elk living.

A total of 142 stool samples were randomly collected from August 2017 to August 2018. The fresh samples were kept in a cold box and immediately transported to the Laboratory. The fecal samples were divided into two, the first part was stored at $4{ }^{\circ} \mathrm{C}$ until egg counting techniques were performed within 3 days and the other part was stored at $-20^{\circ} \mathrm{C}$ for extracting the genomic DNA.

\section{Faecal examination}

The presence of Fasciola spp. eggs in faecal samples was evaluated by a sedimentation-flotation technique according to previous research [11] . Briefly, approximately 10 $\mathrm{g}$ of feces were mixed with $200 \mathrm{ml}$ water and filtered 3 times to get rid of large particles. The filtrate was centrifuged at $700 \times g$ for $4 \mathrm{~min}$, and the supernatant was discarded, the sediment was resuspended in zinc chloride and centrifuged at $180 \times g$ for $3 \mathrm{~min}$. The floating material was collected underneath a cover slip that could stand on the test tube for $2 \mathrm{~min}$. Finally, the slides were microscopically investigated under a $400 \times$ magnification.

\section{Genomic DNA extraction and nest-PCR test}

$200 \mathrm{mg}$ purified stool sample was included in each reaction, then the genomic DNA was extracted according to the Stool DNA kit (Omega D4015-02) instructions. DNA concentration and quality were measured by a Nanodrop 2000 spectrophotometer (Thermo, USA). The DNA samples were stored at $-20^{\circ} \mathrm{C}$ for further research or immediately used for nest-PCR. $12.5 \mu \mathrm{L} 2 \times$ Premix Taq $^{\text {Ta }}$ (TaKaRa, China), $1 \mu \mathrm{L}$ template DNA, $2 \mu \mathrm{L}$ primers and $9.5 \mu \mathrm{L} \mathrm{ddH}_{2} \mathrm{O}$ were included in each $25 \mu \mathrm{L}$ reaction. The reaction conditions were performed according to previous study [12]. Briefly, the cycling conditions were started with a denaturation at $95^{\circ} \mathrm{C} 5 \mathrm{~min}$, followed by 35 cycles of $30 \mathrm{~s}$ at $95^{\circ} \mathrm{C}, 30 \mathrm{~s}$ at $56^{\circ} \mathrm{C}$ (first run) or $57^{\circ} \mathrm{C}$ (second run) and $40 \mathrm{~s}$ at $72{ }^{\circ} \mathrm{C}$, stopped by a final extension at $72{ }^{\circ} \mathrm{C}$ for $7 \mathrm{~min}$. For the first run, the sample genomic DNA was used for template, Fh-FATATTGCGGCCATGGGTTAG and Fh-R- CCAATG ACAAAGTGACAGCG were used for primers, and for second run, template was changed into the PCR product of the first run, and the primers was replaced by n-FTATCACGACGCCCAAAAAGTC and n-R- GATCGC CAAACACACTGACA. The genomic DNA of $F$. hepatica $(160 \mathrm{ng} / \mu \mathrm{L})$ and PBS buffer were used as positive control and the negative control, respectively. Amplification products were observed under UV light after electrophoresis in 3\% agarose gel containing GoldView ${ }^{\mathrm{me}}$ (Solarbio, China), and confirmed by DNA sequencing.

\section{Statistical analysis}

The variation in F. hepatica prevalence of Père David's deer from different years was calculated by $x^{2}$ test using SPSS21 (SAS Institute Inc., Cary, North Carolina, USA). All tests were two sided, and value of $P<0.05$ was considered statistically significant, otherwise the correlation of infection rate in 2 years is not significant [4]. 


\section{Abbreviations}

TCBZ: Triclabendazole; ITS-2: Internal transcribed spacer 2; PBS: Phosphate buffered saline

\section{Acknowledgements}

We thank Dr. Lei Chen from University of Cambridge for assisting with the writing of this manuscript.

\section{Authors' contributions}

SYH, JZG conceived and designed the study. MP, YJR collected the samples. JZG, NY, WMC and YMF performed the laboratory analyses. SYH analyzed the data. All authors critically appraised and interpreted the results. SYH drafted the first version of the manuscript. All authors provided feedback on the manuscript, and read and approved the final version.

\section{Funding}

This work was supported by the National Key Research and Development Program of China (Grant No. 2017YFD0501200), and A Project Funded by the Priority Academic Program Development of Jiangsu Higher Education Institutions (Veterinary Medicine); The funders were not involved in the study design; collection, analysis and interpretation of the data; or in writing the manuscript.

\section{Availability of data and materials}

The datasets used and analyzed during the current study are available from the corresponding author on reasonable request.

\section{Ethics approval and consent to participate}

This study was approved by the Animal Ethics Committee of Yangzhou University and the sample collection was permitted by Ethics Committee of Dafeng Elk National Natural Reserve. All Père David's deer were handled in accordance with good animal practices required by the Animal Ethics Procedures and Guidelines of the People's Republic of China.

\section{Consent for publication}

Not applicable.

\section{Competing interests}

All authors declare that they have no competing interests.

\section{Author details}

${ }^{1}$ Institute of Comparative Medicine, College of Veterinary Medicine, Yangzhou University, and Jiangsu Co-innovation Center for Prevention and Control of Important Animal Infectious Diseases and Zoonosis, and Jiangsu Key Laboratory of Zoonosis, Yangzhou, Jiangsu Province 225009, People's

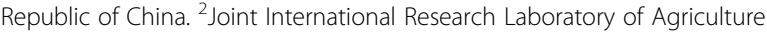
and Agri-Product Safety, the Ministry of Education of China, Yangzhou UniversityYangzhou University, Jiangsu Province, Yancheng, People's Republic of China. ${ }^{3}$ Dafeng Elk National Natural Reserve, Yangzhou, Jiangsu Province, People's Republic of China.

Received: 8 July 2020 Accepted: 24 November 2020

Published online: 03 December 2020

\section{References}

1. Alvarez Rojas CA, Jex AR, Gasser RB, Scheerlinck JP. Techniques for the diagnosis of Fasciola infections in animals: room for improvement. Adv Parasitol. 2014:85:65-107.

2. Kelley JM, Elliott TP, Beddoe T, Anderson G, Skuce P, Spithill TW. Current threat of Triclabendazole resistance in Fasciola hepatica. Trends Parasitol. 2016;32(6):458-69

3. Zhang JL, Si HF, Zhou XZ, Shang XF, Li B, Zhang JY. High prevalence of fasciolosis and evaluation of the efficacy of anthelmintics against Fasciola hepatica in buffaloes in Guangxi, China. Int J Parasitol Parasites Wildl. 2019:8:82-7.

4. Zhang XX, Feng SY, Ma JG, Zheng WB, Yin MY, Qin SY, et al. Seroprevalence and risk factors of Fascioliasis in yaks, Bos grunniens, from three counties of Gansu Province, China. Korean J Parasitol. 2017;55(1):89-93.

5. Rehbein S, Visser M. The endoparasites of Sika deer (Cervus nippon) in Austria. Wien Klin Wochenschr. 2007;119(19-20 Suppl 3):96-101.
6. Arias MS, Pineiro P, Sanchez-Andrade R, Suarez JL, Hillyer GV, Diez-Banos P, et al. Relationship between exposure to Fasciola hepatica in roe deer (Capreolus capreolus) and cattle extensively reared in an endemic area. Res Vet Sci. 2013;95(3):1031-5.

7. Reissig EC, Massone AR, lovanitti B, Gimeno E, Uzal FA. A survey of parasite lesions in wild red deer (cervus elaphus) from argentina. J Wildl Dis. 2018;54:782-9.

8. OToole A, Browne JA, Hogan S, Bassière T, DeWaal T, Mulcahy G, et al. Identity of rumen fluke in deer. Parasitol Res. 2014;113:4097-103.

9. Matsuda K, Kogame S, Niki H, Saito M, Ishiguro Y, Sano Y. Gross and histological lesions in the livers of sika deer with particular emphasis on fascioliasis. J Vet Med Sci. 2020;82(2):125-34

10. Xu AH, Yu XP. Conservation status and sustainable development strategy of Milu( Elaphurus davidianus) in Dafeng. J Anhui Agric Sci. 2019:47(05):107-9.

11. Charlier J, De Meulemeester L, Claerebout E, Williams D, Vercruysse J. Qualitative and quantitative evaluation of coprological and serological techniques for the diagnosis of fasciolosis in cattle. Vet Parasitol. 2008; 153(1-2):44-51.

12. Huang SY, Gong JZ, Yang B, Fan YM, Yao N, Wang CR. Development of a nest-PCR for detection of Fasciola hepatica DNA in the intermediate snail host, Radix cucunorica, and the prevalence in northwestern China. Infect Genet Evol. 2019;75:103984.

\section{Publisher's Note}

Springer Nature remains neutral with regard to jurisdictional claims in published maps and institutional affiliations.

\section{Ready to submit your research? Choose BMC and benefit from:}

- fast, convenient online submission

- thorough peer review by experienced researchers in your field

- rapid publication on acceptance

- support for research data, including large and complex data types

- gold Open Access which fosters wider collaboration and increased citations

- maximum visibility for your research: over $100 \mathrm{M}$ website views per year

At $\mathrm{BMC}$, research is always in progress.

Learn more biomedcentral.com/submissions 